\title{
Provision and awareness for isoniazid preventive therapy among PLHIV in Addis Ababa, Ethiopia
}

\author{
Amenu Wesen ${ }^{1}$ and Getnet Mitike $2^{2^{*}}$
}

\begin{abstract}
Background: The risk of acquiring tuberculosis by People living with HIV (PLHIV) could significantly be reduced through provision of isoniazid preventive therapy (IPT). In Ethiopia, it is neither practiced well nor researched in depth. Our objective was to assess IPT provision and awareness among PLHIV in Addis Ababa City Administration.

Methods: Between February 2008 and May 2008, a cross sectional facility-based survey was conducted by exit interview of 406 PLHIV from six health facilities. The findings were analyzed and described in this report.

Results: The proportion of PLHIV ever had been provided with IPT were 74 of 231 TB free PLHIV (32.0\%) and the proportion of having information about IPT among study participants was $29.8 \%$. Females were about two times more informed about the provision of IPT in their health facilities than males [AOR (95\%Cl): 2.18 (1.31-3.61)].

Conclusions: We conclude that the practice of provision of IPT for PLHIV is high, but there is room for improvement. Provision of INH for TB free PLHIV has to be strengthened with better diagnostic facilities to certainly rule out active TB cases.
\end{abstract}

Keywords: HIV/AIDS, IPT, TB

\section{Background}

The spread of the HIV epidemic throughout sub-Saharan Africa has been accompanied by up to a fourfold increase in the number of TB cases registered by national TB programs [1]. Several researchers have reported the benefit of IPT for PLHIV in reducing the incidence of tuberculosis including in resource poor countries where TB infection rates are very high [2-7]. Interventions for preventing and treating TB include: IPT intensified case finding for active TB and TB infection control [8]. The World Health Organization recommends IPT for all PLHIV in countries with a prevalence of latent TB infection $>30 \%$, and for all PLHIV with documented latent TB infection or exposure to an infectious TB case. In the same policy report it is indicated that the combined use of IPT and antiretroviral therapy among PLHIV significantly reduces new infections [8]. Most IPT studies focused on issues related to adherence by PLHIV $[9,10]$.

\footnotetext{
* Correspondence: getnetmk@gmail.com

${ }^{2}$ School of Public Health, Medical Faculty, Addis Ababa University, Addis

Ababa, Ethiopia

Full list of author information is available at the end of the article
}

Information about the status of IPT provision and awareness of PLHIV regarding IPT in Ethiopia is limited. This is due to the absence of well standardized information flow at all levels and scarcity of research based evidences.

Therefore, this paper attempted to present the status of IPT provision and awareness among PLHIV in Addis Ababa City Administration.

\section{Methods \\ Design}

This is facility-based cross sectional descriptive study which was conducted at one referral hospital and five health centers in Addis Ababa, Ethiopia.

\section{Setting}

The study setting include Zewditu Memorial hospital which is one of the HIV therapy and care hospital and five health centers namely: Bole, T/Haymanot, Gulele, Kazanchis and Woreda 23 health centers to assess the status of IPT provision and awareness among PLHIV attending HIV chronic care clinics. Fifty eight percent of all health facilities in the city provide TB/HIV collaborative services.

\section{() Biomed Central}




\section{Participants}

The study participants include people living with HIV and chronic follow up in the health facilities.

\section{Sampling method}

Using a single population proportion formula with assumption of $50 \%$ prevalence of IPT practice in the country, $5 \%$ margin of error and adding a $5 \%$ allowance for interruption of participation, a sample of 403 study participants was calculated. Randomly selected PLHIV attending HIV chronic care clinics at the selected health facilities in their follow-up care were interviewed at exit. To allocate the number of PLHIV required to interview at each facility, sampling with Proportional allocation to their HIV patient load was applied.

\section{Data collection}

The data collection was conducted from February to May 2008. Three senior VCT counselors conducted the interviews and the principal investigator provided supportive supervisions during data collection by checking completeness and consistency of questionnaires. The interviewers were recruited from health facilities other than the study sites for minimizing interviewer bias. We used interviewer administered questionnaire, which was adapted from WHO guidelines prepared for monitoring and evaluation of TB/HIV activities. As the questionnaire extracted from WHO standard guideline which is the prime source for national guideline for implementation of TB/HIV activities in Ethiopia, its validity and reliability is acceptable.

Ethical clearance was obtained from Institutional Review Board of Addis Ababa University and Addis Ababa City Administration Health bureau. Permission was obtained from authorities of the respective health facilities. The interview was undertaken after ascertaining written consents from study participants. The questionnaire did not include any identifier of the interviewee.

\section{Data analysis}

SPSS version 11 was used for data entry and analysis. Data was analyzed using frequency distribution and characterization of the study population and then logistic regression was applied to identify factors associated with access to IPT as a package of care.

\section{Results}

A total of 406 PLHIV, who were under HIV chronic care follow-up in government health facilities in Addis Ababa City Administration, participated in the study. Out of the total respondents $252(62.1 \%)$ were females.

The mean age $( \pm$ SD) of the study population was 36.27 ( \pm 8.74 ) years. Three hundred and nine $(76.1 \%)$ of the participants were in the age group 25-44, 154 (37.9\%) were married and 128 (31.5\%) were singles, $374(92.1 \%)$ were followers of Christian religion. Fifty two percent had completed high school, $14.5 \%$ had at least a certificate after completing high school. The remaining 17.2\% and $16.5 \%$ accounted for primary completed and having no formal education at the time of the study respectively.

One hundred twenty four (30.5\%), ninety seven (23.9\%) and sixty eight (16.3\%) were privately employed, housewives and government employees by occupation respectively; whereas $93(22.9 \%)$ of study participants were unemployed at the time of data collection.

Close to $85 \%$ of all study participants had become more than six months since they know their positive HIV status. Three hundred and thirty two (81.8\%) of these clients have already started ART in the health facilities. Of those put under highly active antiretroviral therapy (HAART), 188 (46.3\%) were on ART for more than one year.

\section{Awareness about IPT}

The proportion of PLHIV and without active TB who have some information about IPT was $29.8 \%$ (Table 1).

Multiple logistic regression analysis with stepwise selection was used to examine potential effects of the sociodemographic variables including age, sex, educational level, marital status, occupation and other variables on knowledge of access to IPT as a package of care for PLHIV. Females (29.7\%) were more likely to be informed than males (18.8\%) in pertaining to the provision of IPT in their health facilities for those PLHIV having no active TB [AOR (95\%CI): 2.18 (1.31-3.61)].

In addition, those who completed secondary (27.6\%) and post secondary (30.5\%) education were 2.5 and 3.5 times more likely than those non formally educated (14.9\%) to be informed on the availability of IPT [AOR (95\%CI): [2.55 (1.19-5.43), 3.47 (1.37-8.78)] respectively.

Information about the availability of IPT as a package of care among PLHIV in the different health facilities did not reveal statistically significant difference (Table 2).

\section{Provision of IPT}

The proportion of PLHIV who had ever been provided with IPT was 74 of 231 TB free PLHIV (32.0\%). This figure varied with health facilities, for example, in Gulele Health Center no one out of five interviewed PLHIV without active TB had been provided with IPT, whereas; in Kazanchis Health Center eight out of nine eligible PLHIV have been provided with IPT (Figure 1).

\section{Discussion}

As the focus for TB control by most public health experts and clinicians in high burden areas is to find active TB cases for prompt care and therapy, the findings in this study for provision of IPT for eligible TB free PLHIV was $32.0 \%$, this means there were considerable missed 
Table 1 Disease specific characteristics of people living with HIV at HIV chronic care clinics of public facilities in Addis Ababa City Administration, February, 2008.

\begin{tabular}{|c|c|c|}
\hline Variable & Number & Percent \\
\hline \multicolumn{3}{|c|}{ Ever been provided with IPT, $\mathrm{n}=231$ (free from active $T B$ ) } \\
\hline Yes & 74 & 32.0 \\
\hline No & 157 & 68.0 \\
\hline \multicolumn{3}{|l|}{ Awareness about IPT } \\
\hline Yes & 121 & 29.8 \\
\hline No & 285 & 70.2 \\
\hline \multicolumn{3}{|c|}{ Knowledge about IPT service availability in health facilities } \\
\hline Yes available & 104 & 25.6 \\
\hline Not available & 169 & 41.6 \\
\hline I don't know & 133 & 32.8 \\
\hline \multicolumn{3}{|c|}{ If the response to knowledge to IPT is not available, the reasons mentioned were. $(n=169)$} \\
\hline I don't know & 74 & 43.8 \\
\hline Care takers don't order & 92 & 54.4 \\
\hline Other reasons & 3 & 1.8 \\
\hline \multicolumn{3}{|c|}{ Placement of the drug for IPT to be collected, $(n=74)$} \\
\hline HIV clinic & 64 & 86.5 \\
\hline TB clinic & 1 & 1.4 \\
\hline Work place & 9 & 12.2 \\
\hline \multicolumn{3}{|c|}{ Length of being diagnosed for HIV positive } \\
\hline Less than 6 months & 60 & 14.8 \\
\hline 6 months-one year & 87 & 21.4 \\
\hline More than one year & 259 & 63.8 \\
\hline \multicolumn{3}{|l|}{ Length of being on HAART } \\
\hline Less than 6 months & 70 & 17.2 \\
\hline 6 months- one year & 74 & 18.2 \\
\hline More than one year & 188 & 46.3 \\
\hline Not yet started & 74 & 18.2 \\
\hline
\end{tabular}

$n=406$

Table 2 Association of selected variables with Awareness about access to IPT as a package of care among PLHIV, Addis Ababa City Administration, February, 2008.

\begin{tabular}{|c|c|c|c|c|}
\hline \multirow[t]{2}{*}{ Variable } & \multicolumn{2}{|c|}{ Access to IPT as a Package of Care } & \multirow[t]{2}{*}{ Crude Odds Ratio $(95 \% \mathrm{Cl})$} & \multirow[t]{2}{*}{ Adjusted Odds Ratio $(95 \% \mathrm{Cl})$} \\
\hline & Yes (104) & No (302) & & \\
\hline \multicolumn{5}{|l|}{ Sex } \\
\hline Male & 29 & 125 & 1.00 & 1.00 \\
\hline Female & 75 & 177 & $1.83(1.12,2.97)$ & $2.18(1.31,3.61)$ \\
\hline \multicolumn{5}{|l|}{ Educational Status } \\
\hline No formal education & 10 & 57 & 1.00 & 1.00 \\
\hline Primary (1-6) & 18 & 52 & $1.97(0.84,4.66)$ & $2.20(0.93,5.25)$ \\
\hline Secondary (7-12) & 58 & 152 & $2.17(1.04,4.54)$ & $2.55(1.19,5.43)$ \\
\hline Post secondary (12+) & 18 & 41 & $2.50(1.05,5.98)$ & $3.47(1.37,8.78)$ \\
\hline \multicolumn{5}{|c|}{ Time since diagnosed for HIV } \\
\hline Less than 6 months & 10 & 50 & 1.00 & 1.00 \\
\hline 6 months and above & 111 & 235 & $2.36(1.16,4.83)$ & $2.26(1.06,4.85)$ \\
\hline \multicolumn{5}{|l|}{ Type of health facility } \\
\hline Hospital & 74 & 206 & 1.00 & 1.00 \\
\hline Health center & 4 & 20 & $0.53(0.53,1.42)$ & $0.98(0.58,1.64)$ \\
\hline
\end{tabular}

$n=406$ 


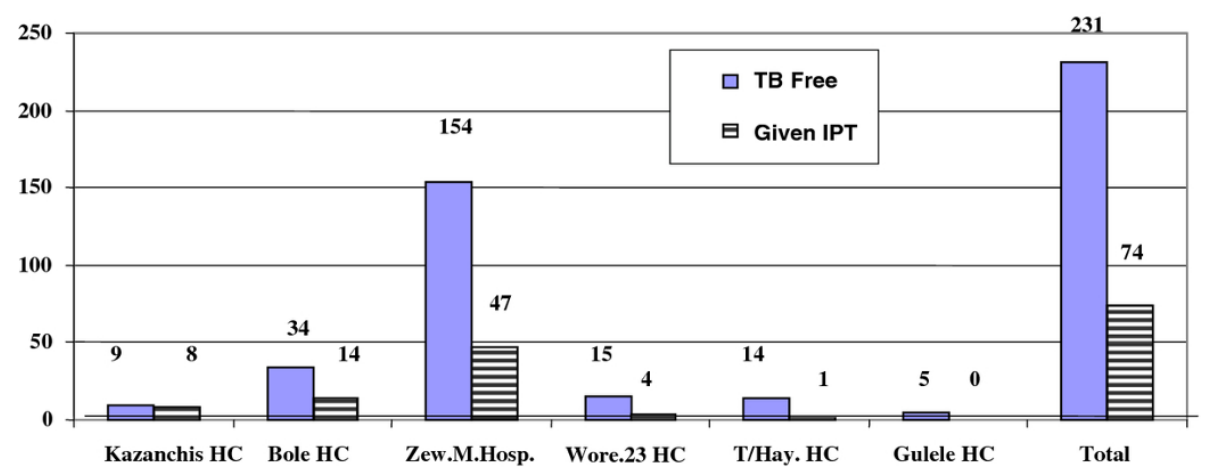

Figure 1 Provision of IPT in relation to TB free people living with HIV across the health facilties, Addis Ababa City Administration, February 2008. $n=231$.

opportunities. In addition, comparable proportion of interviewed study subjects reported to know $(\sim 30 \%)$ about the availability of IPT in the respective health facilities. The low coverage of IPT was due to lack of consistency among health care providers towards providing IPT, shortage of Isoniazid and inequitable availability of investigation setups (X-ray, Fine Needle Aspirations, etc.) at the different health facilities to apparently rule out active TB.

Study participants who completed secondary and post secondary education were found to be better informed about the availability of IPT more than those who were not formally educated. These findings may suggest that educated people are more concerned about their disease patterns and seek additional information better than those of less educated. This might be due to better access to printed media than the less educated counterparts beyond other source of information. This finding was also similar with findings in other countries (China, Malawi and Zambia) [11].

In addition, length of being diagnosed for HIV positive and being informed about IPT had a significant association. Those who knew their HIV positive status for more than six months were about two times more likely to be informed about availability of IPT as a package of HIV care than those who were less than six months. This showed that as people stay longer learning about their HIV status, they become more and more aware of their health conditions and opportunistic infections.

In this study females were more informed about the availability of IPT in their health facilities as a package of HIV care for PLHIV than males. This is in contrary to most findings; a study in rural Vietnamese showed males were two times more informed than the females [12]. Our result was also in contrary to a previous finding where higher proportion of males (87\%) had some kind of educational attainment than females (75\%) indicating better access to printed media in Addis Ababa [13].
However, it is very difficult to make a strong conclusion as the study participants self-select health facilities or it maybe due to men going to private facilities as they are better off in economic status than women.

IPT is one of the key interventions recommended by WHO in 1998 to reduce the burden of TB in PLHIV; yet implementation of IPT had been very low in different countries [14]. The proportion of PLHIV who were free from TB but provided with IPT was only $32.0 \%$. This illustrated the missed opportunities in the prevention of TB in high burden countries such as Ethiopia. However, the proportion of PLHIV in Ethiopia receiving IPT is considerably higher than in most other countries. Globally, only 27,000 PLHIV without active TB were started on IPT $(0.1 \%$ of the 33 million people estimated to be infected with HIV), almost all of whom were in Botswana [15]. In another study in Italy, for example; the number of people actually starting IPT was very low. This was because of the small number who had a positive TST, contraindications to isoniazid and refusal of the eligible to the offered IPT [16].

Generally, provision of IPT among PLHIV in developing countries is linked to operational problems and Ethiopia is not exceptional. There is no system of doing the TST due to lack of national protocol for provision of IPT for eligible PLHIV, lack of trained personnel who do the TST, lack of supply of the test as well as problems related to administration of the TST and follow up.

This study is limited to primary data sources and lacks supportive evidence from secondary data on the TB/ HIV collaborative activities. Interviewer and/or observation bias might not be avoided as all the data collectors were health professionals.

\section{Conclusions}

We conclude that the practice of provision of IPT for PLHIV is high, but there is room for improvement. 
Strengthening of the implementation of IPT among PLHIV through capturing missed opportunities in all health facilities is recommended.

\section{Acknowledgements}

We thank Dr Marina Tadolini, APO-TUB, WHO- Ethiopia, the staffs of National TB and Leprosy Control Team Members at the FMoH-Ethiopia, Addis Ababa City Administration Health Bureau, the study health facilities and all PLHIV who participated in this study.

Finally this study could not have been successful without the resource support from WHO-Ethiopia Country Office and the School of Public Health, Addis Ababa University.

\section{Author details}

${ }^{1}$ Consultant at World Health Organization, South Sudan, Africa. ${ }^{2}$ School of Public Health, Medical Faculty, Addis Ababa University, Addis Ababa, Ethiopia.

\section{Authors' contributions}

AD designed, conducted and analyzed the data as part of his thesis work. GK assisted in the design of the study and conducted analysis of the data. Both contributed in the write up of the manuscript. All authors read and approved the final manuscript.

\section{Competing interests}

The authors declare that they have no competing interests.

Received: 22 July 2011 Accepted: 27 March 2012

Published: 27 March 2012

\section{References}

1. WHO: Guidelines for the implementation of collaborative TB and HIV program activities. Geneva, Switzerland; 2003.

2. Wilkinson D: Drugs for preventing tuberculosis in HIV infected persons. Chocrane Database Sys Rev 2000, 2:CD000171.

3. Pape JW, Jean SS, Hafner A, Johnson WD Jr: Effect of Isoniazid prophylaxis on incidence of active tuberculosis on HIV infection. Lancet 1993, 342(8866):268-272.

4. Fitzgerald DW, Desvarieux M, Severe P, Joseph P, Johnson WD Jr, Pape JW: Effect of post treatment isoniazid on prevention of recurrent tuberculosis in HIV -1 infected individuals: a randomized trial. Lancet 2000, 356(9240):1470-1474.

5. Churchyard GJ, Fielding K, Charalambous S, Day JH, Corbett EL, Hayes RJ, Chaisson RE, De Cock KM, Samb B, Grant AD: Efficacy of secondary isoniazid preventive therapy among HIV-infected Southern Africans: time to change policy. AIDS 2003, 17(14):2063-2070

6. Saenghirunvattana S: Effect of isoniazid prophylaxis on incidence of active tuberculosis among Thai HIV-infected individuals. J Med Assoc Thai 1996, 79(5):265-267.

7. Mwinga A, Hosp M, Godfrey - Faussett P, Quigley M, Mwaba P, Mugala BN, Nyirends O, Luo N, Pobee J, Elliott AM, McAdam KP, Porter JD: Twice weekly tuberculosis preventive therapy in HIV infection in Zambia. AIDS 1998, 12(18):2447-2457.

8. WHO: Three I's Meeting: Intensified Case Finding (ICF), IPT (IPT) and TB Infection Control (IC) for PLHIV. Report of a WHO Joint HIV and TB Department Meeting. World Health Organization HIV Department, Geneva, Switzerland; 2008

9. Szakacs TA, Wilson D, Cameron DW, Clark M, Kocheleff P, Muller FJ, McCArthy AE: Adherence with isoniazid for prevention of tuberculosis among HIV infected adults in South Africa. BMC Infectious Diseases 2006, 6.97, doi 10.1186/147-2334-6.97.

10. Rowe KA, Makhubele B, Hargreaves JH, Porter JD, Hausler HP, Pronyk PM: Adherence to preventive therapy for HIV-positive patients in rural South Africa: Implications for antiretroviral delivery in resource-poor settings. INT J TUBERC LUNG DIS 2005, 9(3):263-269.

11. Liverpool School of Tropical Medicine: EQUI-TB Knowledge Programme: Supporting the design and implementation of the communication and dissemination component of a poverty focused research program on TB.
International. 2005 to 2006.[http://www.healthlink.org.uk/PDFs/consult9906.pdf].

12. Hoa NP, Thorson AE, Long NH, Diwan VK: Knowledge of TB and associated health-seeking behavior among rural Vietnamese. Scand J Public Health 2003, 31:59-65.

13. Central Statistical Agency [Ethiopia] and ORC Macro: Ethiopia Demographic and Health Survey 2005. Addis Ababa. Ethiopia and Calverton, Maryland, USA: Central Statistical Agency and ORC Macro; 2006 [http://www.mofaed. org/Population/ETHIOPIA\%20image.doc].

14. World Health Organization: Policy statement on preventive therapy against TB in PLHIV: Report of a meeting held in Geneva 18-20 February. World Health Organization Global TB Programme and UNAIDS; 1998.

15. World Health Organization: Global TB Control: Surveillance, Planning, Financing. Geneva, World Health Organization; 2008, WHO Report 2008.

16. Girardi E: Feasibility of screening and preventive therapy for TB among intravenous drug users: The SerT/TB Study. International Conference on AIDS. Int Conf AIDS.; 12: 136 (abstract no. 13251) Centro Riferimento AIDS IRCCS L. Spallanzani, Rome, Italy; 1998.

\section{Pre-publication history}

The pre-publication history for this paper can be accessed here: http://www.biomedcentral.com/1472-698X/12/2/prepub

\section{doi:10.1186/1472-698X-12-2}

Cite this article as: Wesen and Mitike: Provision and awareness for isoniazid preventive therapy among PLHIV in Addis Ababa, Ethiopia. BMC International Health and Human Rights 2012 12:2.

\section{Submit your next manuscript to BioMed Central and take full advantage of:}

- Convenient online submission

- Thorough peer review

- No space constraints or color figure charges

- Immediate publication on acceptance

- Inclusion in PubMed, CAS, Scopus and Google Scholar

- Research which is freely available for redistribution 